\title{
Influence of anodisation voltage on the dimension of titania nanotubes
}

\author{
Zainovia Lockman $^{\mathrm{a}, *}$, Srimala Sreekantan ${ }^{\mathrm{a}}$, Syahriza Ismail ${ }^{\mathrm{a}}$, L. Schmidt-Mende ${ }^{\mathrm{b}}$, J.L. MacManus-Driscollc
}

a School of Materials and Mineral Resources Engineering, Engineering Campus, Universiti Sains Malaysia, 14300 Nibong Tebal, Penang, Malaysia

${ }^{\mathrm{b}}$ Department of Materials and Metallurgy, University of Cambridge, Cambridge CB2 3QZ, United Kingdom

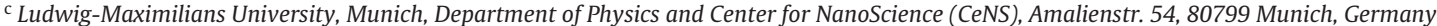

Keywords:

Nanostructured materials

Chemical synthesis

Oxide materials

\begin{abstract}
A B S T R A C T
The formation of self-organised titanium dioxide $\left(\mathrm{TiO}_{2}\right)$ nanotubes array was achieved by anodisation of pure titanium foil in a standard two-electrode bath consisting of $1 \mathrm{M} \mathrm{Na}_{2} \mathrm{SO}_{4}$. Excess $\mathrm{NH}_{4} \mathrm{~F}$ (5 wt\%) was used in this work and the $\mathrm{pH}$ was kept constant at 3. Control over the dimension of the nanotubes was successfully established in this work by altering the anodisation voltage. Three important observations were made: (i) there is a threshold voltage above which nanotubes will form, (ii) within the range of voltages where nanotubes form, samples made at low voltage consist of nanotubes with small pore size $(<40 \mathrm{~nm})$ and nanotubes diameter increases with voltage until a maximum voltage of $25 \mathrm{~V}$ where the nanotubular array started to diminish and (iii) the length of the nanotubes also increases with anodisation voltage. Photocatalytic degradation of methylene blue (MB) was successfully performed on the titania nanotubes with diameter of $100 \mathrm{~nm}$.
\end{abstract}

\section{Introduction}

Titanium dioxide $\left(\mathrm{TiO}_{2}\right)$ is an important semiconductor material for solar energy conversion devices [1,2] and photocatalytic-based devices [3-5]. $\mathrm{TiO}_{2}$ is a photocatalysts when exposed to ultraviolet light and so can be used as an active component for water purification, self-cleaning windows and photoelectrolysis of water to produce $\mathrm{H}_{2}$ [6]. For these applications, nanotubular $\mathrm{TiO}_{2}$ is preferred since the larger surface area enhances the catalysis. Highly ordered vertically oriented nanotubular $\mathrm{TiO}_{2}$ is also attractive for dye-sensitised solar cell to replace nanoparticulates used now [7-9] and for the use as a bioactive material [10]. A challenge remains in regard to the production of self-organised $\mathrm{TiO}_{2}$ nanotubes via a process which could be easily adopted industrially. To date the fabrication process for nanotubular $\mathrm{TiO}_{2}$ are by templating method [11], sol-gel [12] and electrochemical involving anodisation of titanium [13]. Of these methods, anodisation offers the most effective means for producing aligned $\mathrm{TiO}_{2}$ nanotubes. Additionally, it is a simple and cost effective process. In 1999, Zwilling et al. [14] reported on the formation of nanoporous $\mathrm{TiO} 2$ by anodisation of titanium and Ti-6Al-4V in chromic acid solution with out or with hydrofluoric acid addition. Following this work, several works have been reported on the formation $\mathrm{TiO}_{2}$ nanotubes and mechanistic model for the formation of nanotubular $\mathrm{TiO}_{2}$ has been discussed by

\footnotetext{
* Corresponding author. Tel.: +60 645996178.

E-mail address: zainovia@eng.usm.my (Z. Lockman).
}

various authors [15-17]. All these works reach a consensus by stating that $\mathrm{F}^{-}$is a crucial ingredient in the formation of nanotubular structures and diluted $\mathrm{F}^{-}$electrolyte is preferred. Under a typical anodisation potential and time, the length of the nanotubes are often in the range of $200-300 \mathrm{~nm}$ if small amount of $\mathrm{HF}$ is used in an aqueous electrolyte and more than $1 \mu \mathrm{m}$ if non-HF is used $[18,19]$. To further increase the length, organic and viscous electrolytes have been experimented utilising ethylene glycol or glycerol [20,21]. Furthermore, polar organic electrolytes have been reported to enable anodisation at higher voltage for extremely long length nanotubes to be formed [22].

The mechanistic model for nanotubes formation accepted as to date is the attack of pits (formed due to electric field assisted breakdown of the $\mathrm{TiO}_{2}$ layer at the early stage of anodisation) by $\mathrm{F}^{-}$ forming pores which later would transform into cylindrical nanotubular structure. And the growth of nanotubes occurs inwards by electric field dissolution at the bottom part of the nanotubes followed by oxidation at the region. As the pits formation and the dissolution of the bottom part of the nanotubes is related to the electric field that exist across the oxide layer, potential applied during the anodisation is believed to be one of the most important parameters in controlling the dimension of the nanotubes. Additionally, the use of excess $\mathrm{F}^{-}$would increase the growth rate of the nanotubes and hence nanotubes of considerable length can be produced at as a short anodisation time as possible. In order to elucidate the effect of voltage on the dimensions of $\mathrm{TiO}_{2}$ nanotubes in excess $\mathrm{F}^{-}$bath, anodisation experiments were carried out at different voltages. All anodised Ti foils are amorphous and 


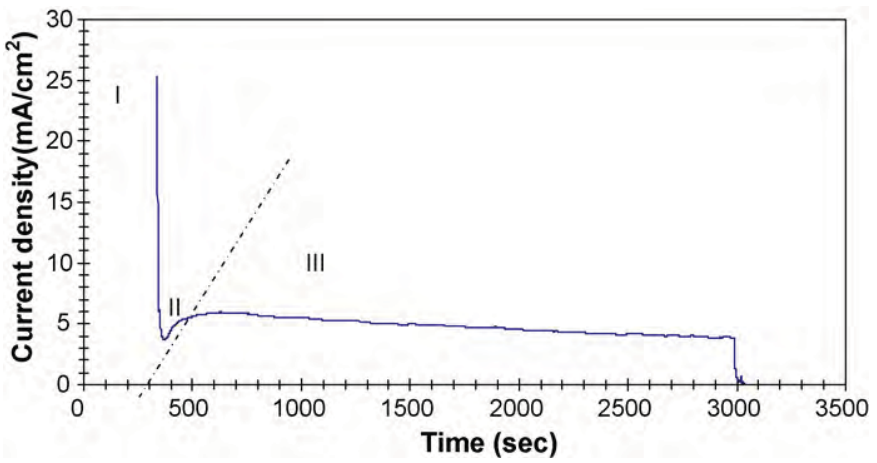

Fig. 1. Current-time plot for titanium anodised at $20 \mathrm{~V}$ in $5 \mathrm{wt} \% \mathrm{NH}_{4} \mathrm{~F}$ solution for $30 \mathrm{~min}$.

must be heat treated to induce desired crystalline phase. In here, to verify the photocatalytic property of the nanotubes, study on the decomposition of methylene blue was performed.

\section{Experimental}

High purity titanium foils (99.96\% purity, Advent Research Materials, England) anodised in a two-electrode electrochemical cell at room temperature. Prior to anodisation, the foil was cleaned with ethanol and sonically cleaned in iso-propano for $15 \mathrm{~min}$. After drying, each foil was cut into $1 \mathrm{~cm} \times 3 \mathrm{~cm}$ and with $1 \mathrm{~cm} \times 2 \mathrm{~cm}$ area exposed to the bulk electrolyte which consisted of $1 \mathrm{M} \mathrm{Na}_{2} \mathrm{SO}_{4}$ added to it $5 \mathrm{wt} \%$ $\mathrm{NH}_{4} \mathrm{~F} . \mathrm{H}_{2} \mathrm{SO}_{4}$ was added to the solution to reduce the $\mathrm{pH}$ to 3 . The foil was connected to a dc power (GW Instek, GPS 3303) supply using platinum rod as a counter electrode. The voltage was ramped from the open-circuit to the desired potential ranging from $1 \mathrm{~V}$ to $30 \mathrm{~V}$. The sweep rate was kept constant at $0.5 \mathrm{~V} / \mathrm{s}$.

The morphologies of the anodised foils were studied using a field emission scanning electron microscope (FE-SEM) Zeiss Supra 35. Transmission electron microscopy (TEM) (Philips 420T) was used to examine the shape and size of the nanotubes formed. Raman spectroscopy (Jobin Yvon HR 800UV) with a $20 \mathrm{~mW}$ argon ion laser, and X-ray diffraction analyses were done using Philip model PW 1729 on the samples to determine the crystallinity of the as-anodised and annealed samples. Annealing was done in a typical horizontal furnace at $480^{\circ} \mathrm{C}$ and $600^{\circ} \mathrm{C}$ in oxygen with heating and cooling rates of $10^{\circ} \mathrm{C} / \mathrm{min}$ for $1 \mathrm{~h}$. Photocatalytic properties of annealed nanotubes were measured by the decomposition of methylene blue (MB). The samples were placed horizontally in a testing cell containing $10 \mathrm{ppm}$ MB. UV was provided by a commercial UV lamp (TUV 18 W UV-C Germicidal light) with radiation wavelength of $\sim 350 \mathrm{~nm}$. Absorption spectra were measure by UV-vis spectroscopy system (PerkinElmer Lambda 35 ) with a wavelength range between $200 \mathrm{~nm}$ and $900 \mathrm{~nm}$.

\section{Results and discussion}

\subsection{Anodisation at different voltages}

Fig. 1 depicts the current-time curve during anodisation of titanium at $20 \mathrm{~V}$ in $5 \mathrm{wt} \% \mathrm{NH}_{4} \mathrm{~F}$ solution. In the formation of selforganised nanotubular structure by anodisation, two important aspects must be considered: (a) pore initiation and (b) pore propagation and growth. At the initial stage of anodisation (as marked I in Fig. 1), a thin $\mathrm{TiO}_{2}$ layer forms on the surface of titanium. This corresponds to passivation behaviour of the foil and can be described by reaction (1):

$\mathrm{Ti}+\mathrm{H}_{2} \mathrm{O} \rightarrow \mathrm{TiO}_{2}+4 \mathrm{H}^{+}+4 \mathrm{e}^{-}$

Localised breakdown due to high field effect across the passivated layer would induce the pore initiation. Such process, termed field assisted dissolution would polarise and weaken Ti-O bond resulting in the dissolution of oxide [15]. As a result, pits will form on the surface of the oxide which will act as pore nucleation centres [23]. The current would rise again during this process, as marked II in Fig. 1.

The mechanism of pore propagation and growth is associated with the voltage applied and composition of the electrolyte used for anodisation. Pore growth would originate at the pore nucleation centres i.e. the pits by chemical dissolution process. In acidic and fluorine contained electrolyte, the chemical dissolution will form soluble $\left[\mathrm{TiF}_{6}\right]^{2-}$ ions (reaction (2)). The use of excess fluorine ions in the electrolyte would enhance the chemical dissolution, forming pores at faster rate [16]:

$\mathrm{TiO}_{2}+6 \mathrm{NH}_{4} \mathrm{~F}+4 \mathrm{H}^{+} \rightarrow\left[\mathrm{TiF}_{6}\right]^{2-}+2 \mathrm{H}_{2} \mathrm{O}+6 \mathrm{NH}_{4}{ }^{+}$

At the initial stage of anodisation, field assisted dissolution dominates chemical dissolution since the electric field across the electrode is very high. As the anodisation proceeds and oxide thickens, the chemical dissolution will take over field assisted dissolution. Chemical dissolution will increase the size of the pores and the density of pores also increases. The growth and propagation of the pores occur by inward movement at the oxide|metal interface. When this happens, discrete, hollow-like cylindrical oxide will be formed which would develop into the nanotubular structure. The growth of the nanotubes is marked as region III in Fig. 1. As the oxide layer at the bottom of the pore is subjected to chemical dissolution, it becomes thinner with time. If anodisation is conducted in fluorine concentrated solution, the rate of attack would be faster thus thickness reduction would be faster. As the thickness reduces, electric field assisted dissolution will reoccur at this region. By this process, the pores will penetrate inside the Ti and the nanotubes become longer and longer. However, as voltage is continuously applied, anodisation would reoccur at the bottom of the pore, forming nanotubes with closed bottom. The growth of the nanotubes is therefore determined by the amount of fluorine in the bath and the degree of electric field dissolution i.e. the voltage applied. When the anodisation voltage is very high, the rate of electric field dissolution at the barrier layer inside the nanotubes would be higher hence longer nanotubes would be produced.

The top part (oxide|electrolyte interface) of the nanotubes is exposed to electrolyte with high concentration of $\mathrm{F}^{-}$and $\mathrm{H}^{+}$, therefore is subjected to chemical etching. The rate of the chemical etching at the oxide|electrolyte interface and the rate of nanotubes grow inwards at the oxide|metal interface will eventually determine the length of the nanotubes. If the solution is made too acidic (low pH), the chemical etching at the oxide|electrolyte will be faster resulting in shorter nanotubes.

The effect of anodisation voltage on the diameter of the nanotubes can be related to the number of pits formed during the early stage of the anodisation process. It is inferred that samples anodised at high voltage will suffer from severe electric field dissolution forming more pits at an early stage of the anodisation. These pits will be etched to form larger pores. As growth of the pores dominates, the resulting diameter of the nanotubes will be larger when anodisation is performed at higher voltage. At lower anodisation voltage, less electric field dissolution occurs forming $\mathrm{TiO}_{2}$ with smaller diameter pores. By understanding the mechanism of the nanotubes formation, the dimension (diameter and length) of the nanotubes can be predicted just simply by applying the right voltage across the electrode.

The diameter of the resulting nanotubes formed as well as the length is studied in this work as a function of anodisation voltage from $1 \mathrm{~V}$ to $30 \mathrm{~V}$. It is suspected that at a very low anodisation voltage, pores with small diameter will result and the length of the tube would be shorter as well. Fig. 2 shows the morphologies of anodised foils at different voltages. No nanotubes form for samples anodised at $1 \mathrm{~V}$ and $5 \mathrm{~V}$ (Fig. 2(a) and (b)). In Fig. 2(a), the inset shows a low magnification image of the anodised foil at $1 \mathrm{~V}$ and the higher magnification image is taken from the circled area of the inset. Under this condition, the voltage seems to be inadequate for continuous formation of $\mathrm{TiO}_{2}$ film, however the Ti foil was severely etched, revealing the grain boundaries of the Ti and in some parts 

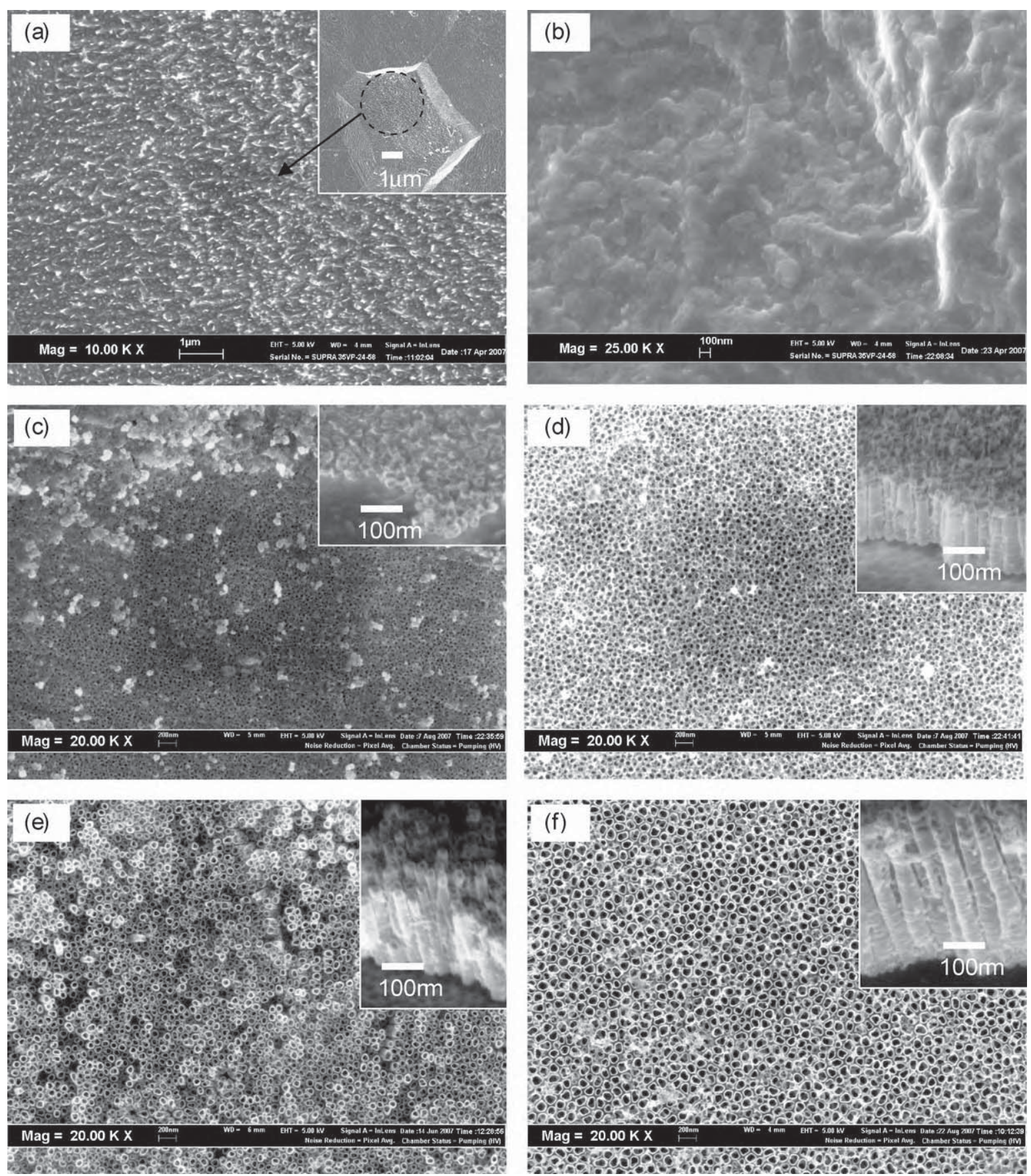

Fig. 2. SEM morphologies of samples made at (a) $1 \mathrm{~V}$, (b) $5 \mathrm{~V}$, (c) $10 \mathrm{~V}$, (d) $12 \mathrm{~V}$, (e) $15 \mathrm{~V}$ and (f) $20 \mathrm{~V}$ in $5 \mathrm{wt} \% \mathrm{NH}_{4} \mathrm{~F}$ solution for $30 \mathrm{~min}$ (pH=3).

of the foil, a needle-like structure (most likely of $\mathrm{TiO}_{2}$ ) is observed. At $5 \mathrm{~V}$, as seen in Fig. 2(b), the $\mathrm{TiO}_{2}$ layer is more compact but no nanotubular structure can be seen.

Samples anodised at $12 \mathrm{~V}, 15 \mathrm{~V}$ and $20 \mathrm{~V}$ gave the surface morphologies consisting of ring-like structure which is related to the opening of the nanotubes (Fig. 2(d), (e) and (f)). Insets are the cross-sectional morphologies to show the nanotubular structure. Samples made at $10 \mathrm{~V}$ are discussed later. As seen in Fig. 2(d), (e) and (f), the length of the nanotubes increased from $100 \mathrm{~nm}$ to $200 \mathrm{~nm}$ to $500 \mathrm{~nm}$ for samples anodised at $12 \mathrm{~V}, 15 \mathrm{~V}$ and $20 \mathrm{~V}$ respectively. As anticipated, at higher anodisation voltage, the electric field dissolution at the barrier layer occurs much faster thus the deepening rate of the pore is faster forming longer nanotubes. The diameter of the nanotubes increases from $50 \mathrm{~nm}$ to $70 \mathrm{~nm}$ to $80 \mathrm{~nm}$ indicating that the pore growth occurs at higher anodisation voltage increasing the diameter.

Samples that were made at $10 \mathrm{~V}$ (Fig. 2(c)) show surface morphology and consisted of a ring-like structure with diameter of less than $40 \mathrm{~nm}$, suggesting the beginning of pore formation. The inset in Fig. 2(c) is a cross-section gathered from some part of the structure. As seen the thickness of this ring-like structure is very small. The threshold voltage for $\mathrm{TiO}_{2}$ nanotube formation is, therefore, at around $10 \mathrm{~V}$ in the $5 \mathrm{wt} \% \mathrm{NH}_{4} \mathrm{~F}$ solution $(\mathrm{pH}=3)$.

The sample prepared at $10 \mathrm{~V}$ was then subjected to a longer anodisation time to test whether this would result in further chemical etching of the oxide and hence uniform formation of $\mathrm{TiO}_{2}$ nanotubes. In Fig. 3(a) and (b), samples prepared for $60 \mathrm{~min}$ and $100 \mathrm{~min}$ at $10 \mathrm{~V}$ are shown. Insets are the cross-section images and 

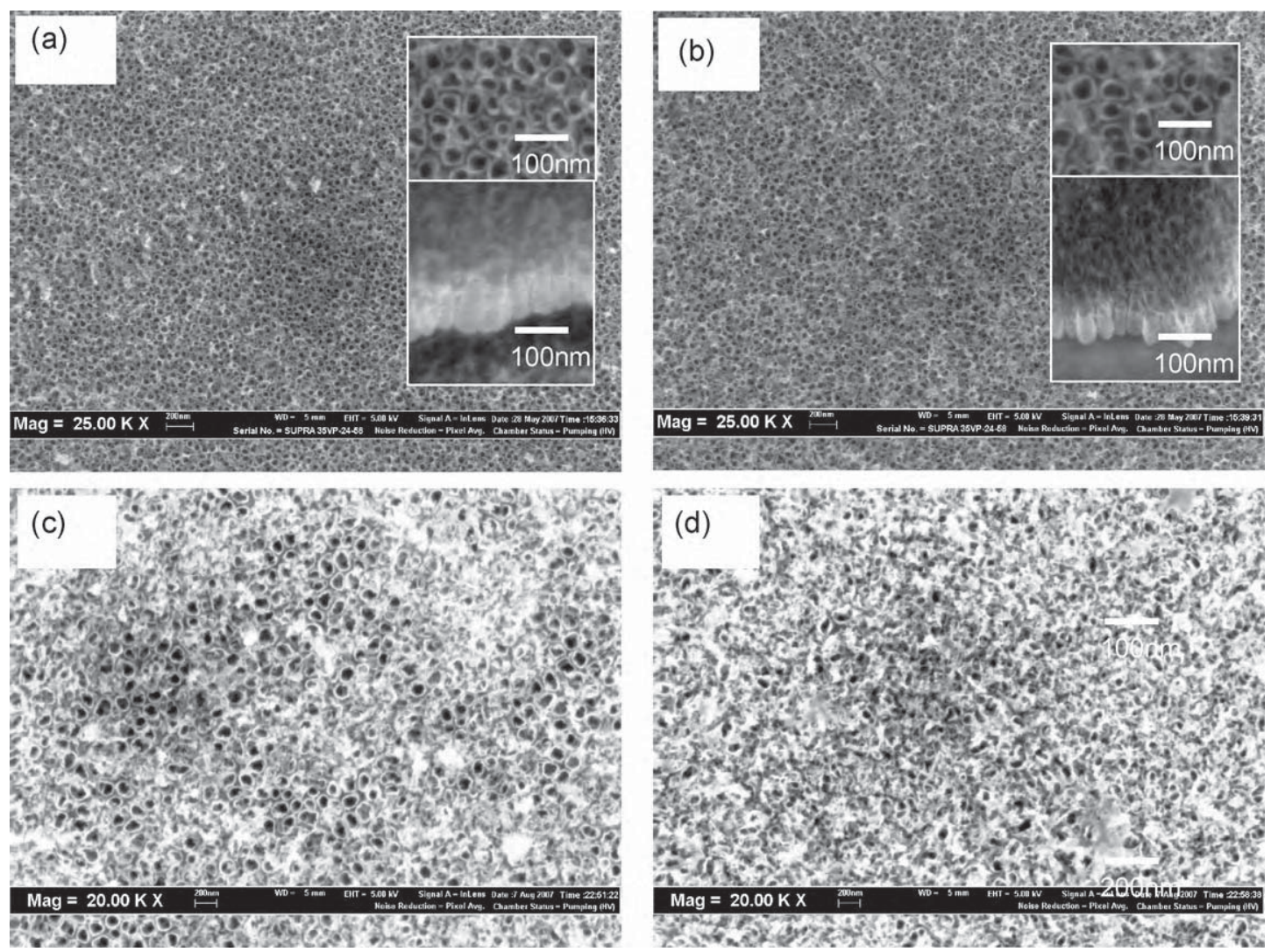

Fig. 3. SEM images of titanium anodised at (a) $10 \mathrm{~V}$ for $60 \mathrm{~min}$, (b) $10 \mathrm{~V}$ for $100 \mathrm{~min}$, (c) $25 \mathrm{~V}$ for $30 \mathrm{~min}$ and (d) $30 \mathrm{~V}$ for $30 \mathrm{~min}$ in $5 \mathrm{wt} \% \mathrm{NH}_{4} \mathrm{~F}$ bath (pH=3).

higher magnification images of the same sample. As anticipated, when the anodisation times were increased the anodised foils were consisted of $\mathrm{TiO}_{2}$ nanotubes. The length of the nanotubes is averaged at $100 \mathrm{~nm}$ and the diameter is $<40 \mathrm{~nm}$.

Anodisation experiments at voltages $>20 \mathrm{~V}$ were carried out to seek the possibility of increasing the length and diameter of the nanotubes further. Surface morphologies of $\mathrm{TiO}_{2}$ formed at $25 \mathrm{~V}$ and $30 \mathrm{~V}$ are shown in Fig. 3(c) and (d) for samples anodised for $30 \mathrm{~min}$. As oppose to the increase on the diameter of the nanotubes, the nanotubes structure starts to be deteriorated at $25 \mathrm{~V}$ and com- pletely lost at $30 \mathrm{~V}$. A spongy-like porous structure was observed. Under the condition where voltage is too high, electric filed dissolution is believed to occur too rapidly, polarising and weakening the Ti-O bond not only at the bottom part of the nanotubes but also across the length of the nanotubes as well. This results in randomly porous oxide structure as opposed to self-organised structure. A maximum voltage at which nanotubular $\mathrm{TiO}_{2}$ persists in $5 \mathrm{wt} \% \mathrm{NH}_{4} \mathrm{~F}$ solution is therefore $25 \mathrm{~V}$.

TEM analysis of sample made at $20 \mathrm{~V}$ shows the shape of a single nanotube which consisted of a closed bottom with a barrier layer
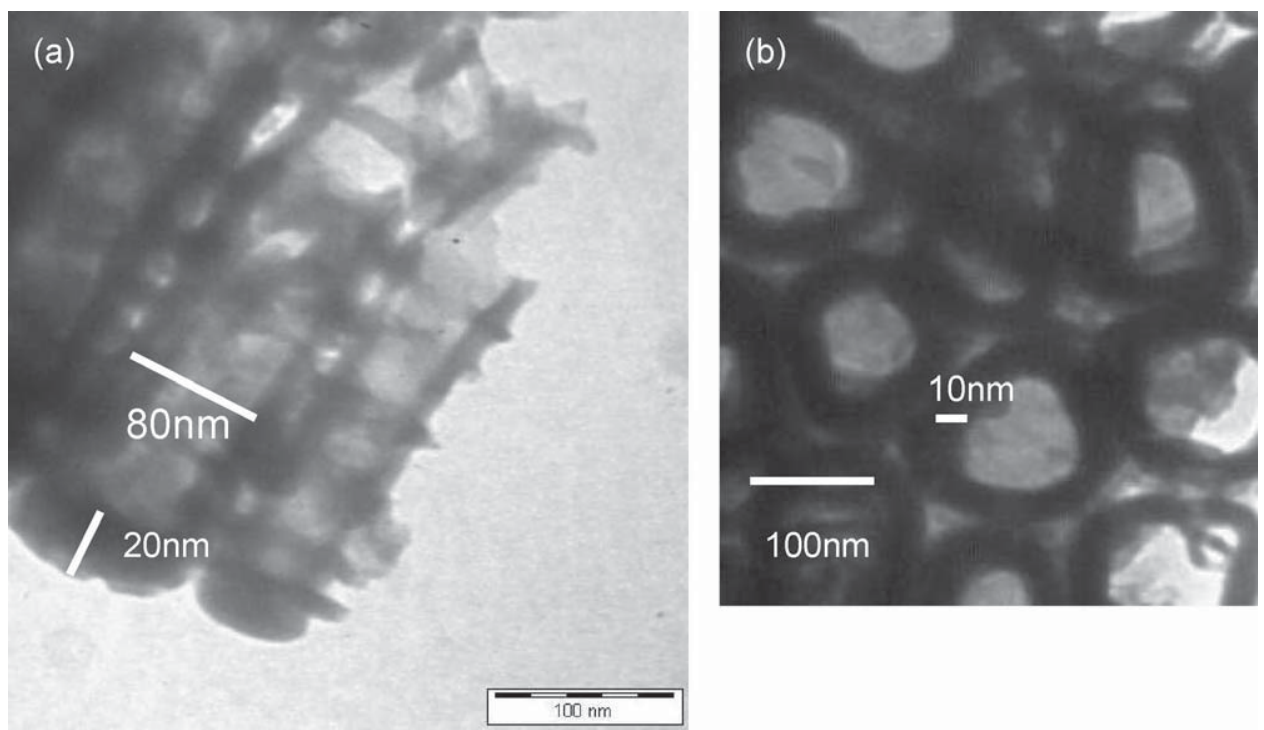

Fig. 4. TEM micrographs of anodised titanium made at $20 \mathrm{~V}$ for $30 \mathrm{~min}$ in $5 \mathrm{wt} \% \mathrm{NH}_{4} \mathrm{~F}$ bath (a) to show the cross-section and (b) the ring-like structure. 


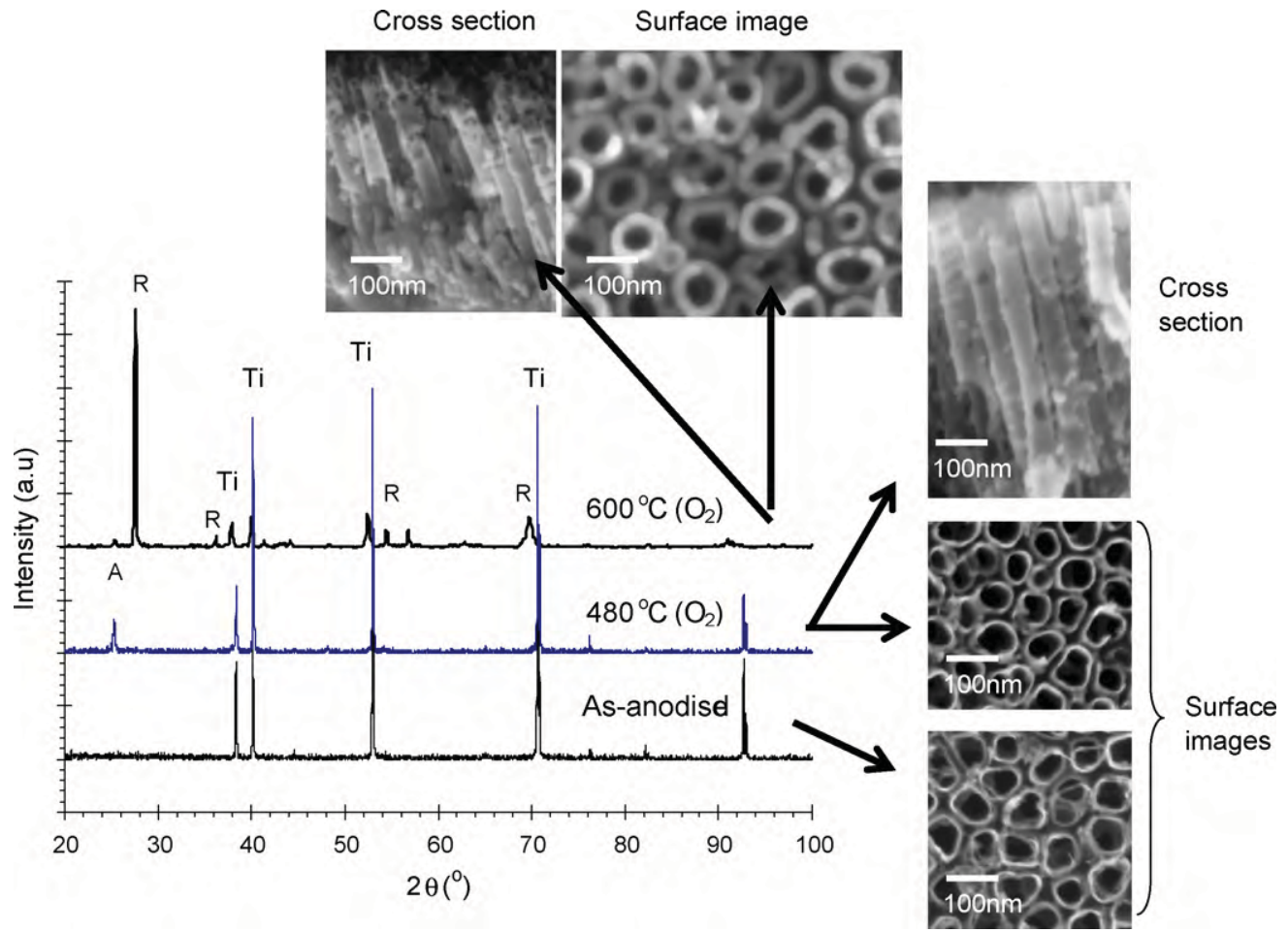

Fig. 5. XRD patterns of annealed (at $480^{\circ} \mathrm{C}$ and $600^{\circ} \mathrm{C}$ in $\mathrm{O}_{2}$ ) and as-anodised samples. Insets are the surface morphologies for as anodised and the cross-sectional image for annealed samples. $\mathrm{R}$ indicates rutile titania and $\mathrm{A}$ indicates anatase titania.

thickness of $20 \mathrm{~nm}$ as in Fig. 4(a). The thickness of each nanotube wall is around $10 \mathrm{~nm}$ as shown in Fig. 4(b) and appears to be uniform throughout the length of the nanotubes. The diameter to length ratio of the sample is around $1: 5(0.2)$ for samples made at $20 \mathrm{~V}$ whereas the ratio is $1: 2.5(0.4)$ for samples made at $12 \mathrm{~V}$ after $30 \mathrm{~min}$ of anodisation.

\subsection{Raman spectra and $X$-ray diffraction analysis}

Samples made at $20 \mathrm{~V}$ for 30 min were annealed to study the crystallinity of the oxide and its integrity after heat treatment. Annealing was done at $480^{\circ} \mathrm{C}$ and $600^{\circ} \mathrm{C}$ in oxygen for $1 \mathrm{~h}$. XRD patterns of the sample before and after annealing are shown in Fig. 5. The pattern for the as-anodised film indicates that the $\mathrm{TiO}_{2}$ nanotubes are amorphous; only peaks from the Ti foils can be detected. Raman spectroscopy (Fig. 6) indicates that, in fact, anatase titania may present by considering extremely broad peaks at

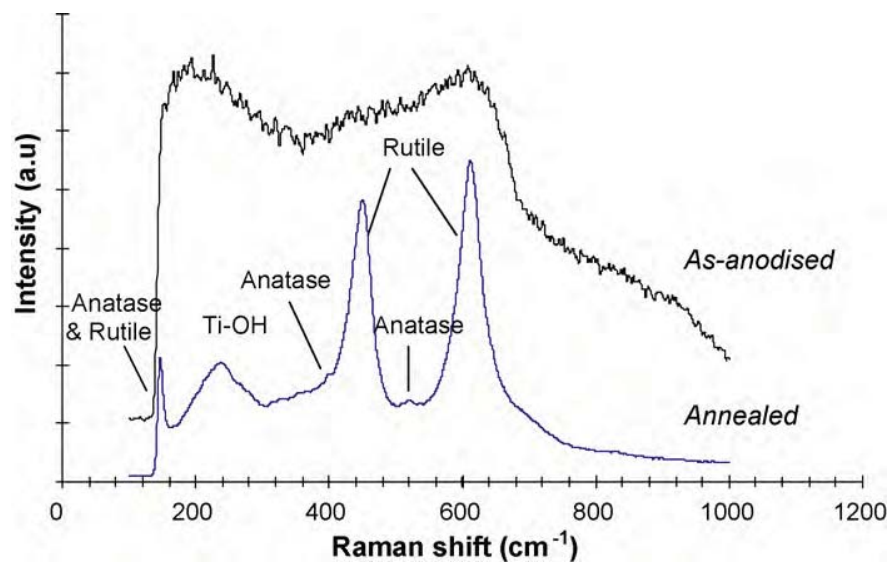

Fig. 6. Raman spectra for as-anodised and annealed sample at $600{ }^{\circ} \mathrm{C}$ in oxygen.
$140-300 \mathrm{~cm}^{-1}$ and $400-700 \mathrm{~cm}^{-1}$. Similar findings were reported by Zhao et al. [17]. XRD pattern of heat treated sample at $480^{\circ} \mathrm{C}$ shows a peak at $2 \theta=25^{\circ}$ belonging to anatase titania. Rutile phase is identified from a peak at $2 \theta=28^{\circ}$ for sample annealed at $600^{\circ} \mathrm{C}$. Phase transformation may occur at $600^{\circ} \mathrm{C}$ in the wall of the nanotubes by the reorientation of the Ti-O bond forming rutile titania. However, the rutile phase may also be due to the product of oxidation of the substrate and growth of new oxide along the nanotube walls. Similar findings were reported by other authors on the origin of the rutile detection of heat treated nanotubes [24,25]. The inset in Fig. 5 shows the morphologies of $\mathrm{TiO}_{2}$ nanotubes before and after annealing at $480^{\circ} \mathrm{C}$ and $600^{\circ} \mathrm{C}$. As seen from the figures, annealing did not change the surface and cross-sectional morphologies at $480^{\circ} \mathrm{C}$ but did increase the wall thickness for sample annealed at $600^{\circ} \mathrm{C}$. Furthermore as seen from the cross-section image of the sample annealed at $600^{\circ} \mathrm{C}$, severe oxidation of the barrier layer can be seen, shortening the nanotubes. Therefore, the rutile detection from the samples annealed at $600^{\circ} \mathrm{C}$ may originate from the oxidised Ti substrate and the new grains which grow along the nanotube walls.

According to Qian et al. [26], titania nanotubes prepared by sol-gel method is consisted of a mixture of rutile, anatase and a $\mathrm{Ti}-\mathrm{OH}$ phase. Rutile can be detected at $144 \mathrm{~cm}^{-1}\left(\mathrm{~B}_{1 \mathrm{~g}}\right), 447 \mathrm{~cm}^{-1}$ $\left(E_{g}\right), 612 \mathrm{~cm}^{-1}\left(A_{1 g}\right)$ and $826 \mathrm{~cm}^{-1}\left(B_{2 g}\right)$. Raman shifts associated to anatase are at $144 \mathrm{~cm}^{-1}\left(\mathrm{Eg}_{\mathrm{g}}\right), 196 \mathrm{~cm}^{-1}\left(\mathrm{Eg}_{\mathrm{g}}\right), 397 \mathrm{~cm}^{-1}\left(\mathrm{~B}_{1 \mathrm{~g}}\right)$, $516 \mathrm{~cm}^{-1}\left(\mathrm{~A}_{1 \mathrm{~g}}\right), 519 \mathrm{~cm}^{-1}\left(\mathrm{~B}_{1 \mathrm{~g}}\right)$ and $640 \mathrm{~cm}^{-1}\left(\mathrm{E}_{\mathrm{g}}\right)$. The Ti-OH could be detected at $266 \mathrm{~cm}^{-1}$. The Ti-OH peak which they claimed to be related to the nanotubular structure of the titania disappears when heat treated. In this work, from Fig. 6, three relatively strong Raman shift associated to rutile titania can be detected at $146 \mathrm{~cm}^{-1}$, $449 \mathrm{~cm}^{-1}$ and $614 \mathrm{~cm}^{-1}$. The fourth Raman shift which should be seen at $\sim 830 \mathrm{~cm}^{-1}$ can be barely observed in the spectrum. A much broader and lower intensity peak at $245 \mathrm{~cm}^{-1}$ can instead be detected which could be due to $\mathrm{Ti}-\mathrm{OH}$ within the tubular structure as previously reported by Qian et al. [26]. Along with these four Raman active modes, two weaker peaks at $398 \mathrm{~cm}^{-1}$ and $517 \mathrm{~cm}^{-1}$ 


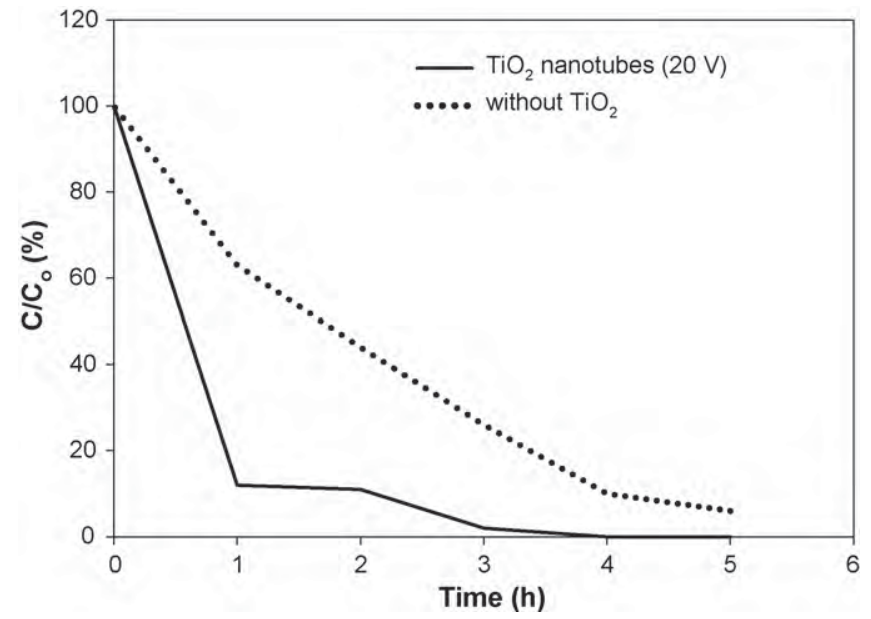

Fig. 7. Photocatalytic degradation of methylene blue under UV with and without $\mathrm{TiO}_{2}$ nanotubes.

are seen in Fig. 6. Both are associated to anatase titania which indicates that the transformation from anatase to rutile has not completed at this temperature and the incompletion could be due to the size of the wall thickness which hinder the reorientation of the Ti-O bond for rutile formation.

\subsection{Degradation studies of methylene blue (MB)}

The degradation activity of $\mathrm{TiO}_{2}$ nanotubes was evaluated by the study of MB degradation in an aqueous solution, under UV radiation. Fig. 7 shows the degradation of $M B$ as a function of time on $100 \mathrm{~nm}$ diameter $\mathrm{TiO}_{2}$ nanotubes. For comparison degradation study was performed without $\mathrm{TiO}_{2}$. As $\mathrm{MB}$ can be degraded under UV without the need of a photocatalyst, the degradation does occur but at a much slower rate compared to when the dye was exposed to $\mathrm{TiO}_{2}$ nanotubes. In the presence of $\mathrm{TiO}_{2}$ nanotubes, more than $80 \%$ of the dye was degraded after $1 \mathrm{~h}$ of exposure and complete degradation can be seen after $3 \mathrm{~h}$ of exposure.

\section{Conclusion}

$\mathrm{TiO}_{2}$ nanotubes were successfully formed after $30 \mathrm{~min}$ of anodisation of pure titanium foil in a standard two-electrode bath consisting $5 \mathrm{wt} \% \mathrm{NH}_{4} \mathrm{~F}$ at constant $\mathrm{pH}$ of 3 at voltage ranges from $10 \mathrm{~V}$ to $25 \mathrm{~V}$. When the anodisation voltage was further increased, the formation of nanotubes persisted and their diameters and length were increased. The average diameters of the nanotubes were $80 \mathrm{~nm}, 70 \mathrm{~nm}$ and $50 \mathrm{~nm}$ for samples anodised at $20 \mathrm{~V}, 15 \mathrm{~V}$ and $12 \mathrm{~V}$ respectively. Anodisation above $25 \mathrm{~V}$ resulted in the formation of randomly porous $\mathrm{TiO}_{2}$ and the nanotubes structure diminishes. Control over the dimensions of the nanotubes was, therefore, successfully established in this work simply by controlling anodising voltage and fast rate of formation was thought to occur due to the use of excess fluorine solution. Raman analysis of as-anodised samples revealed that the samples are weakly crystalline and annealed samples are consisted of a mixture of rutile and anatase phases with more crystalline rutile titania for samples annealed at $600^{\circ} \mathrm{C}$. The degradation of MB was successful in the presence of $\mathrm{TiO}_{2}$ nanotubes with $100 \%$ degradation after $3 \mathrm{~h}$ of exposure.

\section{Acknowledgments}

The authors acknowledge partial funding from the European Commission (Marie Curie Excellence Grant 'NanoFen', MEXT-CT2004-014156) and Universiti Sains Malaysia Short Term Grant 2007: 6035226 .

\section{References}

[1] K.G. Ong, O.K. Varghese, G.K. Mor, K. Shankar, C.A. Grimes, Sol. Energy Mater Sol. Cells 91 (2007) 250

[2] M. Grätzel, Nature 414 (2001) 338

[3] A. Fujishima, T.N. Rao, D.A. Tyrk, J. Photochem. Photobiol. C 1 (2000) 1.

[4] O. Carp, C.L. Huisman, A. Reller, Solid State Chem. 32 (2004) 33.

[5] S. Sreekantan, Z. Lockman, R. Hazan, M. Tasbihi, L.K. Tong, A.R. Mohamed, J. Alloys Compd. 485 (2009) 478.

[6] M. Paulose, G.K. Mor, O.K. Varghese, K. Shankar, C.A. Grimes, J. Photochem. Photobiol. A: Chem. 178 (2006) 8.

[7] J.M. Macak, H. Tsuchiya, A. Ghicov, P. Schmuki, Electrochem. Commun. 7 (2005) 1133.

[8] K. Shankar, J. Bandara, M. Poulose, H. Wietasch, O.K. Varghese, G.K. Mor, T.J LaTempa, M. Thelakkat, C.A. Grimes, Nano Lett. 8 (6) (2008) 1654

[9] G.K. Mor, K. Shankar, M. Poulose, O.K. Varghese, C.A. Grimes, Nano Lett. 6 (2) (2006) 215.

[10] X.-F. Xiao, R.-F. Liu, T. Tian, J. Alloys Compd. 466 (2008) 356.

[11] P. Hoyer, Langmuir 12 (1996) 1411.

[12] N. Venkatachalam, M. Palanichamy, V. Murugesan, Mater. Chem. Phys. 104 (2007) 454.

[13] D. Gong, C.A. Grimes, O.K. Varghese, W. Hu, R.S. Singh, Z. Chen, E.C. Dickey, J. Mater. Res. 16 (2001) 3331.

[14] V. Zwilling, E. Darque-Ceretti, A. Boutry-Forveille, D. David, M.Y. Perrin, M Aucouturier, Surf. Interface Anal. 27 (1999) 629

[15] G.K. Mor, O.K. Varghese, M. Paulose, K. Shankar, C.A. Grimes, Sol. Energy Mater. Sol. Cells 90 (2006) 2011.

[16] J.M. Macak, H. Hildebrand, U. Marten-Jahns, P. Schmuki, J. Electroanal. Chem. $621(2008) 254$

[17] J. Zhao, X. Wang, R. Chen, L. Li, Solid State Commun. 134 (2005) 705.

[18] J.M. Macak, H. Tsuchiya, L. Taveira, S. Aldabergerova, P. Schmuki, Angew. Chem. Int. Ed. 44 (2005) 7463.

[19] L.V. Taveira, J.M. Macak, H. Tsuchiya, L.F.P. Dick, P. Schmuki, J. Electrochem. Soc. 152 (2005) B405.

[20] K.S. Raja, T. Gandhi, M. Misra, Electrochem. Commun. 9 (2007) 1069.

[21] M. Paulose, K. Shankar, S. Yoriya, H.E. Prakasam, O.K. Varghese, G.K. Mor, T.A Latempa, A. Fitzgerald, C.A. Grimes, J. Phys. Chem. B 110 (2006) 16179.

[22] K. Shankar, G.K. Mor, H.E. Prakasam, S. Yoriya, M. Paulose, O.K. Varghese, C.A. Grimes, Nanotechnology 18 (6) (2007) 11, 065707.

[23] K. Yasuda, J.M. Macak, S. Berger, A. Ghicov, P. Schmuki, J. Electrochem. Soc. 154 (9) (2007) C472.

[24] O.K. Varghese, D. Gong, M. Paulose, C.A. Grimes, J. Meter. Res. 18 (2003) 156

[25] J. Zhao, X. Wang, T. Sun, L. Li, J. Alloys Compd. 434-435 (2007) 792.

[26] L. Qian, Z. Du, S. Yang, Z. Jin, J. Mol. Struct. 749 (2005) 103. 